\title{
Flexural retrofitting of reinforced concrete bridge pier type cross-sections with carbon fiber reinforcing plastics
}

\author{
G. C. Manos \& V. Kourtides \\ Laboratory of Strength of Materials and Structures, \\ Department of Civil Engineering, Aristotle University, \\ Thessaloniki, Greece
}

\begin{abstract}
Results and conclusions are presented from an experimental investigation with identical column-specimens, which were constructed with prototype materials, having a height of $1600 \mathrm{~mm}$ and a cross section $300 \mathrm{~mm}$ by $200 \mathrm{~mm}$. They represent models of a part of a bridge-pier near its base, with or without partial confinement of Carbon Fibre Reinforcing Plastic (CFRP) layers. They were subjected to compressive loads as this type of stress field is expected to develop at the base of such vertical members under combined vertical loads and seismic actions, where undesired compression failure may develop. The retrofitting of this type of reinforced concrete cross sections, with $\mathrm{h} / \mathrm{b}$ ratio larger than 1.5 , is aimed at prohibiting, up to a point, such compression failure. This type of partial confinement may also be applied to retrofitting similar vertical structural members with non-accessible sides. With the successful application of this partial confinement, an increase of almost 50\% was observed in the compression capacity of the test specimens. Moreover, the deformability of these specimens was substantially increased, demonstrating the effectiveness of this type of partial confinement. It was also demonstrated from the experimental sequence that critical factors for the effectiveness of this partial CFRP confinement were the type of anchorage of the CFRP layers on the body of the cross-section and the number of CFRP layers.

Keywords: carbon fibre reinforcing plastics, retrofitting, bridge pier, reinforced concrete.
\end{abstract}




\section{Introduction}

The upgrading of reinforced concrete $(\mathrm{R} / \mathrm{C})$ cross-sections, with one side rather longer than the other $(\mathrm{h} / \mathrm{b}>1.5)$, by partial application of CFRP (Carbon Fibre Reinforcing Plastic) confinement is investigated here (Figures 1 and 2). This partial application of CFRP confinement is aimed at the retrofitting of bridgepier type $\mathrm{R} / \mathrm{C}$ cross-sections in order to prohibit, up to a point, the development of premature compressive failure at the base of the pier due to combined compression and flexure from seismic loads (Figure 1, Kawashima [1]). The performance of such structural elements was studied extensively in the past (Pinto [4]). This type of partial confinement may also be applied to upgrading vertical structural members with non-accessible sides. Design guidelines for rectangular FRP jackets applied on rectangular columns have been proposed with the limitation that the cross-sections have aspect ratio $\mathrm{h} / \mathrm{b}<1.5$ (Tsonis [5]). For higher aspect ratios it is recommended designing a circular or oval jacket. However, it is expected that for rectangular cross sections with aspect ratios larger than 1.5 the radius of a circular or rectangular jacket will be too large and will result in ineffectual confinement and will prove costly and impractical. For this reason it is desirable to investigate alternative schemes for increasing the confinement of rectangular cross-sections with relatively large aspect ratio without resorting to complete circular or oval jackets. Such a scheme is studied here using CFRP layers that do not extend all around the cross-section (Figure 2 "partial confinement"). To compensate for the fact that the CFRP layers do not enclose the cross-section entirely, anchorage of these layers must be provided, as shown schematically at the bottom of figure 2. To this end, a laboratory investigation was carried out to study the effectiveness of such partial confinement together with alternative anchorage schemes. As will be explained, this effectiveness was tested by subjecting the specimens only to compressive loads. Despite this limitation, as will be demonstrated from the results of this investigation, the most significant aspects of the critical factors for this "partial confinement" scheme were brought to light.

\section{Test specimens}

The initial cross-section, which formed the basis of the tested specimens, had an aspect ratio $\mathrm{h} / \mathrm{b}$ equal to 2.5 . This is a rectangular cross section of a bridge pier model structure, which was tested both at the laboratory and at the Volvi-Greece European Test Site in the framework of the European project Euro-Risk (Manos et al. [2, 3]). This cross section was intentionally designed to develop flexural mode of failure at the base of the pier; moreover, it was desirable to find ways to retrofit such specimens by prohibiting premature compression failure at the base by means of partial CFRP confinement. The effectiveness of the partial CFRP confinement is studied by subjecting the tested specimens only to pure compressive loads. This type of stress field is expected to develop in the base of such vertical members under combined vertical loads and seismic actions, where undesired compression failure may develop (figure 1). In order to limit the 
maximum level of compressive loads required to bring to failure such a crosssection with the loading arrangements available, the tested specimens had a cross section (figure 2) of $200 \mathrm{~mm}$ by $300 \mathrm{~mm}$ instead of $200 \mathrm{~mm}$ by $500 \mathrm{~mm}$ of the initial cross-section for the bridge pier specimens tested both at the laboratory and at the test site under combined compression and flexure Manos et al. [2, 3]). Moreover, in order for the tested specimens to form compression failure at the same part of the cross-section where such failure would develop at the base of the initial bridge pier model (figure 1), one part of the tested cross-section was left identical to the initial cross-section (the one that is marked in figure 3 as weak) whereas the remaining part was strengthened both with longitudinal and in particular, with transverse reinforcement (the one marked in figure 3 as strong). In this way, with the compression capacity of the weak part being smaller than that of the strong part, the compression failure was expected to develop at the weak part. This proved to be correct during the experiments, as will be shown in the following sections. The CFRP partial confinement was applied at the weak part, as is shown at the right hand side of figure 3 with the anchor bolts being applied at the part of the CFRP layers attached to the strong part. By studying the resulting bearing capacity and mode of failure under compression of the tested specimens (with or without partial confinement) the effectiveness of such a repair scheme could be demonstrated and classified as listed in Table 1.

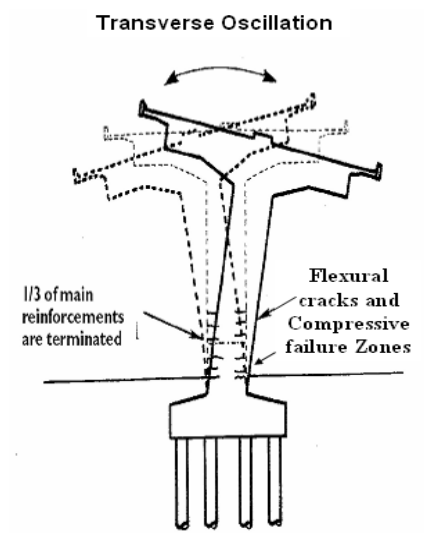

Figure 1: Bridge pier compression failure mode.

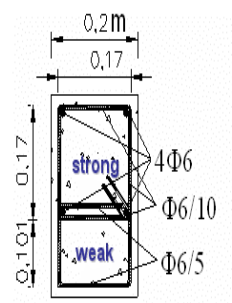

Nature of the problem

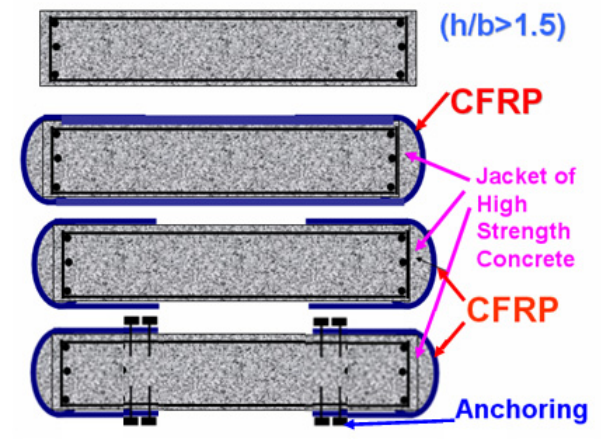

Figure 2: Partial confinement provided by CFRP layers anchored with bolts.

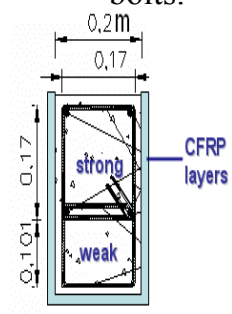

Figure 3: Test specimens without and with partial CFRP confinement. 
Table 1: $\quad$ Effectiveness of the partial confinement.

\begin{tabular}{|l|l|l|}
\hline Compression failure mode & Capacity Increase * & Effectiveness \\
\hline Weak part & Small increase & Low \\
\hline Weak part & Considerable increase & Considerable \\
\hline $\begin{array}{l}\text { Both weak and strong } \\
\text { parts }\end{array}$ & Substantial increase & Very effective \\
\hline
\end{tabular}

* (compared to the unconfined specimens)

\subsection{Construction of test specimens}

Ten identical specimens were constructed and eight of them were used in the current experimental sequence (see Table 2). All specimens were reinforced in the same way and were cast at the same time with the same mixture aiming for similar plain concrete strength values. The total height of the specimens was $1600 \mathrm{~mm}$. They had a mid-part height of $580 \mathrm{~mm}$ that was left to develop the compression failure The cross section of this mid-part was the one shown in figure 3, including the two distinct parts (the weak and the strong). The two edges (top and bottom) of the specimens, with a height of $510 \mathrm{~mm}$ each, were confined during the experiment with strong steel brackets covering these parts from all sides thus prohibiting any compressive failure developing at those two edges (see figure 4). The partial CFRP confinement was attached only on the three sides of these specimens covering the weak part of the cross-section and leaving the fourth side (of the strong part) free without any CFRP layers (figure 3).

Table 2: $\quad$ Test specimen with their corresponding concrete strength.

\begin{tabular}{|c|c|c|c|}
\hline $\begin{array}{c}\text { Virgin } \\
\text { Specimens }\end{array}$ & $\begin{array}{c}\text { CFRP } \\
\text { Confinement }\end{array}$ & Repaired Specimens & $\begin{array}{l}\text { Plain Concrete } \\
\text { Strength }(\mathrm{Mpa})^{*}\end{array}$ \\
\hline $\begin{array}{l}\text { Specimen } 1 \\
\text { Test } 1\end{array}$ & No & $\begin{array}{l}\text { Test } 2 \\
3+(2) \text { CFRP }\end{array}$ & 28.0 \\
\hline $\begin{array}{l}\text { Specimen 1a } \\
\text { Test } 1\end{array}$ & 3 CFRP layers & $\begin{array}{l}\text { Test } 2 \\
3 \text { GFRP }\end{array}$ & 25.8 \\
\hline $\begin{array}{c}\text { Specimen } 3 \\
\text { Test } 1\end{array}$ & No & $\begin{array}{l}\text { Test } 2 \\
3+(2) \text { CFRP }\end{array}$ & 27.6 \\
\hline $\begin{array}{c}\text { Specimen } 3 \mathrm{a} \\
\text { Test } 1\end{array}$ & 5 CFRP layers & $\begin{array}{l}\text { Test } 2 \\
5 \text { CFRP }\end{array}$ & 27.6 \\
\hline $\begin{array}{c}\text { Specimen } 4 \\
\text { Test } 1\end{array}$ & 5 CFRP layers & & 27.7 \\
\hline $\begin{array}{c}\text { Specimen } 4 \mathrm{a} \\
\text { Test } 1\end{array}$ & 5 CFRP layers & & 27.7 \\
\hline $\begin{array}{c}\text { Specimen } 5 \\
\text { Test } 1\end{array}$ & $\begin{array}{l}5+(2) \\
\text { CFRP layers }\end{array}$ & $\begin{array}{l}\text { Test } 2,5+2 \text { CFRP } \\
\text { Test } 3,5+2 \text { CFRP } \\
\text { Test } 4 \quad 7 \text { CFRP }\end{array}$ & 27.6 \\
\hline $\begin{array}{l}\text { Specimen } 5 \mathrm{a} \\
\text { Test } 1\end{array}$ & No & $\begin{array}{l}\text { Test 2, } 7 \text { CFRP } \\
\text { Test } 3 \text { 7+4 CFRP }\end{array}$ & 25.8 \\
\hline
\end{tabular}


There were 8 virgin specimens, namely 1, 1a, 3. 3a, 4, 4a, 5, and 5a (Table 2). These specimens were tested in their virgin state in which some of them were without partial CFRP confinement whereas the rest had the partial CFRP confinement applied to them from the beginning. The second column of table 2 indicates the partial confinement condition of the virgin specimens. The testing sequence of these virgin specimens is signified as Test 1. Most of these specimens were repaired after they had reached their limit state during their previous test. In all the repaired specimens the CFRP partial confinement was applied. This sequential test number of the repaired specimens is signified as Test 2 (for the $1^{\text {st }}$ repair), Test 3 (for the $2^{\text {nd }}$ repair) etc. (see column 3 of Table 2). In the same column the number of CFRP layers used in the partial confinement for the repaired specimens is also indicated. The total number of specimens, virgin and repaired, was seventeen. In Table 2 the unconfined concrete compressive stress is also listed, found from cylinders with diameter $150 \mathrm{~mm}$ and $300 \mathrm{~mm}$ height; these cylinders were obtained during the casting of each virgin specimen.

The anchorage of the CFRP layers was applied along the two long sides, which were attached to the sides of both the weak and the strong parts of the cross-section (figure 3). The main load that was applied was axial compression, although in limited specimens the axial compression was combined with bending, which is not reported here. From the observed behaviour, the effectiveness of the applied partial confinement could be deduced. As shown in table 1, this judgment was based on the level of the bearing capacity combined with the type of compression failure that was formed (at the weak or strong part). Moreover, the observed behaviour of the various parts of the test specimens, such as the CFRP layers and their anchorage, helped to identify the factors that bear an adverse or beneficial influence on these aspects of the behaviour.

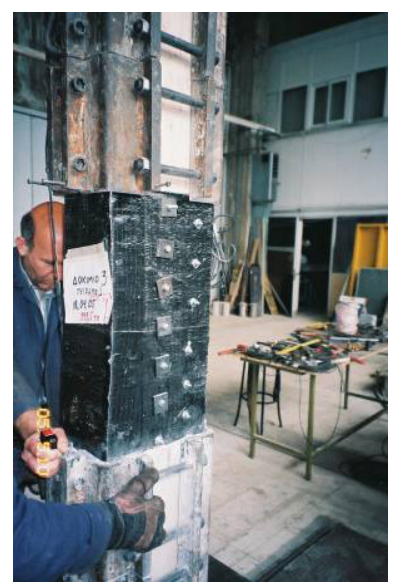

Figure 4: Confining steel brackets and partial CFRP confinement at the mid-part. 
Table 3: Summary of test results together with the basic specimen characteristics.

\begin{tabular}{|c|c|c|c|c|c|c|}
\hline $\begin{array}{l}\text { Spec. } \\
\text { No }\end{array}$ & Virgin & Repaired & $\begin{array}{l}\text { CFRP } \\
\text { layers }\end{array}$ & Anchors & $\begin{array}{c}\text { Average } \\
\text { Stress at } \\
\text { failure } \\
\text { (Mpa) }\end{array}$ & $\begin{array}{l}\text { Failure } \\
\text { Mode }\end{array}$ \\
\hline $\begin{array}{c}1 \\
\text { Test } 1\end{array}$ & Yes & No & No & No & $\begin{array}{c}41.12 \\
(146.9 \%)^{*}\end{array}$ & Weak part \\
\hline $\begin{array}{c}1 \\
\text { Test } 2\end{array}$ & No & $\begin{array}{c}\text { Yes/ } \\
\text { EMACO }\end{array}$ & $3(+2)$ & yes & $\begin{array}{c}41.69 \\
(148.9 \%)\end{array}$ & Bolts \\
\hline $\begin{array}{c}1 \mathrm{a} \\
\text { Test } 1\end{array}$ & Yes & No & 3 & Yes & $\begin{array}{c}45.78 \\
(177.4 \%)\end{array}$ & $\begin{array}{c}\text { Pull out } \\
\text { Anchors-1 }\end{array}$ \\
\hline $\begin{array}{c}3 \\
\text { Test } 1\end{array}$ & Yes & No & No & No & $\begin{array}{c}40.79 \\
(147.7 \%)\end{array}$ & Weak part \\
\hline $\begin{array}{c}3 \\
\text { Test } 2\end{array}$ & No & Yes & $3(+2)$ & Yes & $\begin{array}{c}45.78 \\
(165.9 \%)\end{array}$ & anchorage \\
\hline $\begin{array}{c}3 \mathrm{a} \\
\text { Test } 1\end{array}$ & Yes & No & 5 & Yes & $\begin{array}{c}47.09 \\
(170.6 \%)\end{array}$ & anchorage \\
\hline $\begin{array}{c}3 \mathrm{a} \\
\text { Test } 2\end{array}$ & No & $\begin{array}{c}\text { Yes/ } \\
\text { EMACO }\end{array}$ & 5 & Yes & $\begin{array}{c}42.51 \\
(154.0 \%)\end{array}$ & anchorage \\
\hline $\begin{array}{c}4 \\
\text { Test } 1\end{array}$ & Yes & No & 5 & Yes weak & $\begin{array}{c}46.60 \\
(168.2 \%)\end{array}$ & anchorage \\
\hline $\begin{array}{c}4 \mathrm{a} \\
\text { Test } 1\end{array}$ & Yes & No & 5 & $\begin{array}{c}\text { Yes } \\
\text { weak }\end{array}$ & $\begin{array}{c}45.53 \\
(164.4 \%)\end{array}$ & anchorage \\
\hline $\begin{array}{c}5 \\
\text { Test } 1\end{array}$ & Yes & No & $5(+2)$ & Yes strong & $\begin{array}{c}53.96 \\
(195.5 \%)\end{array}$ & $\begin{array}{c}\text { Steel } \\
\text { bracket }\end{array}$ \\
\hline $\begin{array}{c}5 \\
\text { Test } 2\end{array}$ & Yes & - & $5(+2)$ & Yes strong & $\begin{array}{c}55.26 \\
(200.2 \%)\end{array}$ & $\begin{array}{c}\text { Steel } \\
\text { bracket }\end{array}$ \\
\hline $\begin{array}{c}5 \\
\text { Test } 3\end{array}$ & - & $\begin{array}{c}\text { Top / } \\
\text { EMACO }\end{array}$ & $5(+2)$ & Yes Strong & $\begin{array}{c}53.96 \\
(195.5 \%)\end{array}$ & $\begin{array}{l}\text { CFRP mid- } \\
\text { height }\end{array}$ \\
\hline $\begin{array}{c}5 \\
\text { Test } 4\end{array}$ & No & $\begin{array}{c}\text { Yes/ } \\
\text { EMACO }\end{array}$ & 7 & Yes Strong & $\begin{array}{c}58.86 \\
(213.3)\end{array}$ & $\begin{array}{c}\text { Strong } \\
\text { stirrups }\end{array}$ \\
\hline $\begin{array}{c}5 \mathrm{a} \\
\text { Test } 1\end{array}$ & Yes & No & No & No & $\begin{array}{c}40.88 \\
(158.4 \%)\end{array}$ & Weak part \\
\hline $\begin{array}{c}5 \mathrm{a} \\
\text { Test } 2\end{array}$ & No & Yes & 7 & Yes Strong & $\begin{array}{c}57.23 \\
(221.8 \%)\end{array}$ & $\begin{array}{l}\text { CFRP mid- } \\
\text { height }\end{array}$ \\
\hline $\begin{array}{c}5 \mathrm{a} \\
\text { Test } 3\end{array}$ & No & Yes & $7+4$ & Yes Strong & $\begin{array}{c}60.17 \\
(233.2 \%)\end{array}$ & Strong part \\
\hline
\end{tabular}

* As \% of the corresponding plain concrete strength.

\subsection{Instrumentation to obtain the average stress-strain behaviour}

Apart from monitoring the compressive load, the deformations of the mid-part were also continuously recorded throughout each experiment with displacement measurements taken at each side of the cross-section. Eight displacement sensors (two at each side) were employed to record the deformations of the mid-part. Although the deformation of this mid-part was far from uniform, as could be seen from the obtained displacement measurements of the weak and strong parts 
(figure 5), the average axial displacement, which was found by averaging the measured displacement values at all four sides of each specimen, is mostly used here as an indication of the deformability of each specimen. By dividing this average axial displacement by the height of the mid-part an average axial strain could also be obtained in this way. The following discussion of the observed behaviour of each specimen is based on diagrams of average axial stress versus average axial strain found from the previously described averaging process. More detailed study on the obtained non-uniform deformability for each specimen will be carried out at a future stage. An additional measurement that was obtained during the experimental sequence was the axial strain that developed at the CFRP layers of the partial confinement of the mid-part. These CFRP strain measurements are an additional indication of the effectiveness of the partial confinement.

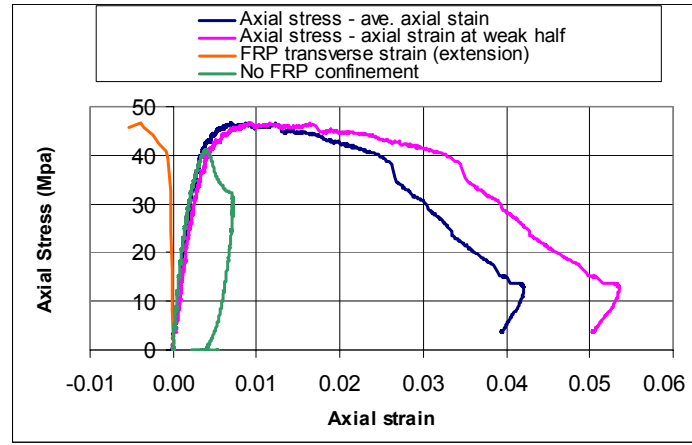

Figure 5: Spec. 4, Test 1 (5 layers CFRP) comparison spec. 1 Test 1 (no confinement).

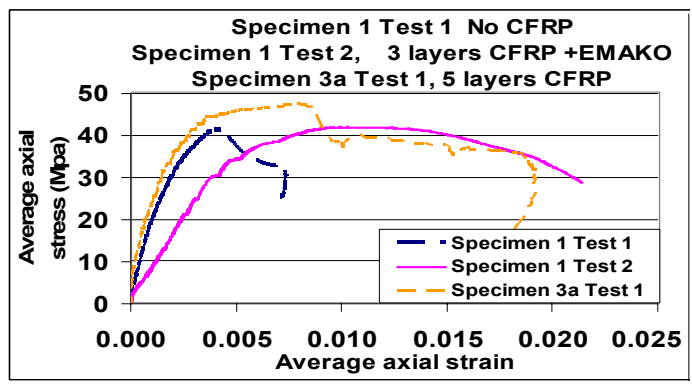

Figure 7: Partial confinement of low effectiveness.

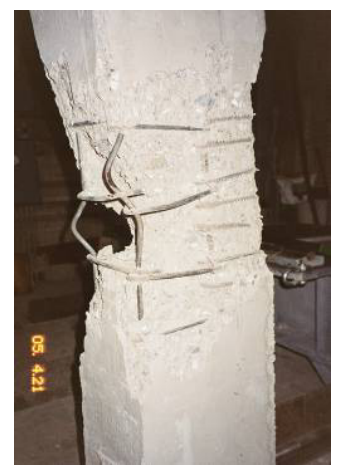

Figure 6: Virgin specimen without confinement.

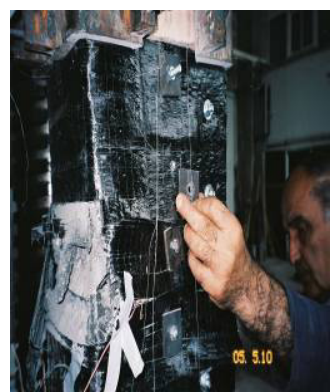

Figure 8: Failure of anchor bolt. 


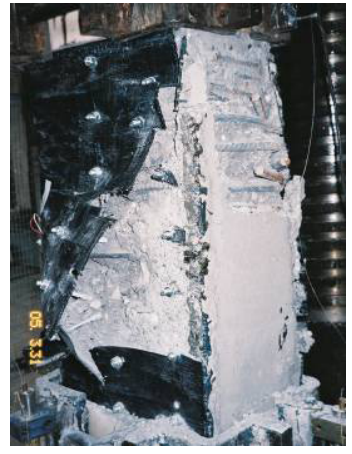

Figure 9: Failure of anchor bolts. Low effectiveness of partial confinement.

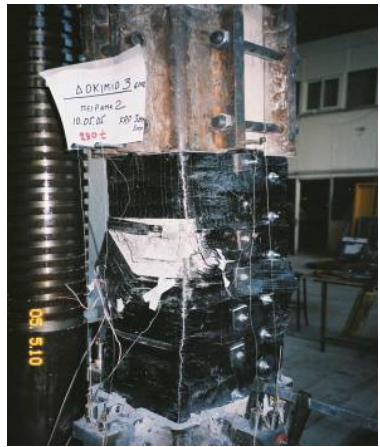

Figure 10: Tensile failure of CFRP layers. Considerable effectiveness of partial confinement.

\section{Discussion of test results}

\subsection{Partial confinement of low effectiveness}

In figure 7 the obtained behaviour of specimen 1 (Test 2) with 3 CFRP layers and specimen $3 \mathrm{a}$ (Test 1) with 5 CFRP layers is compared with specimen 1 test 1 (no partial confinement). Specimen 1 test 2 was formed from specimen 1 test 1 by repairing the failed specimen 1 test 1 with special (low shrinkage) concrete as well as with 3 layers of CFRP forming the partial confinement. This repaired specimen failed in compression with almost the same capacity as the previouslytested virgin test with no partial confinement (figure 6), but with larger deformability. The effectiveness of the partial confinement is low and it is due to the failure of the anchor bolts of the applied confinement. In figure 7 the observed behaviour of specimen $3 \mathrm{a}$ Test 1 is also included. This is a virgin specimen that had a 5-CFRP layer partial confinement. Despite the increase in the CFRP layers, the observed effectiveness of the partial confinement is low as was for specimen 1 test 2, again because of the failure of the anchor bolts.

The failed virgin specimen without the partial confinement is shown in figure 6 whereas figure 8 and 9 depicts the failure of the anchor bolts for the "low effectiveness" partial confinement. In figure 11 the observed behaviour of specimen 4 test 1 is depicted. This was a virgin specimen with 5 CFRP layers partial confinement. In this case, a certain alteration was applied in the anchor bolts, by increasing their length. However, this was not sufficient to improve accordingly the effectiveness of the partial confinement, which was again linked to the failure of the anchor bolts. 


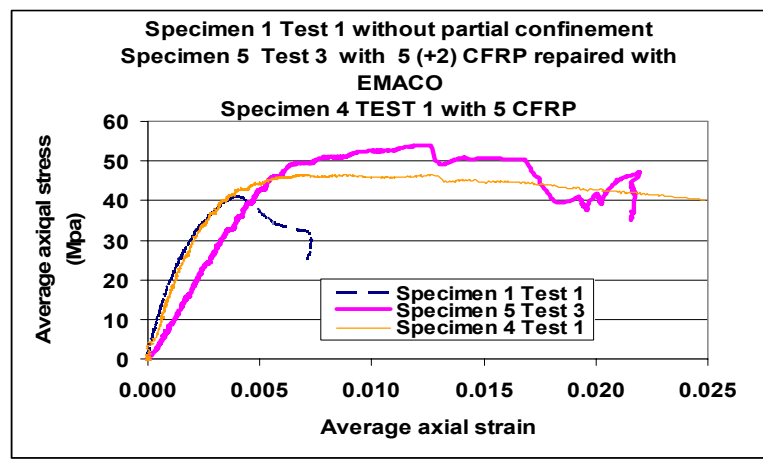

Figure 11: Partial confinement of considerable effectiveness.

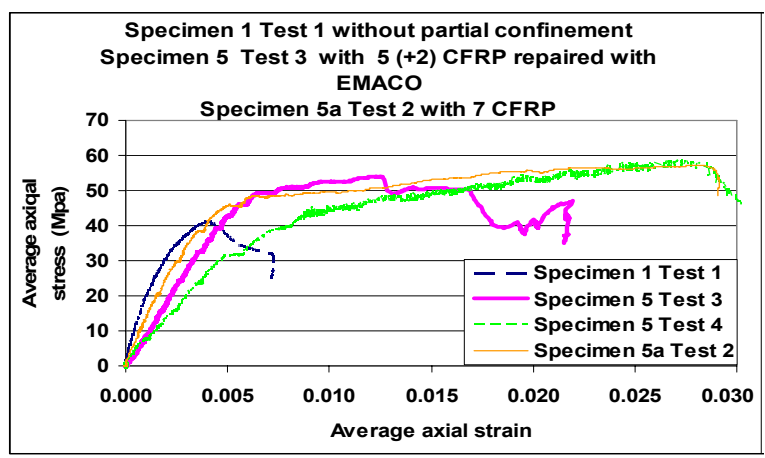

Figure 13: Very effective partial confinement.

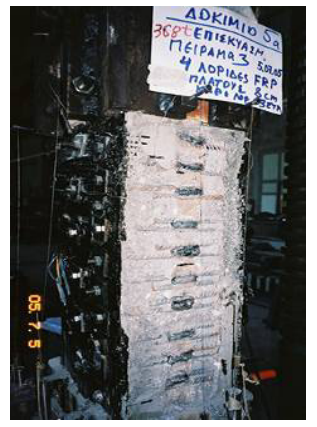

Figure 12: Strengthening of the stirrups for the strong part.

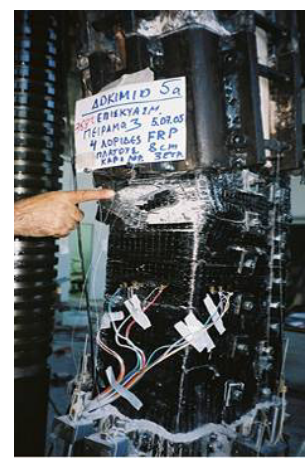

Figure 14: Failure of the CFRP layers of the mid-part.

\subsection{Partial confinement of considerable effectiveness}

In figure 11 the obtained behaviour of specimen 5 (Test 3) with $5(+2)$ CFRP layers is compared to specimen 1 test 1 (no partial confinement). Specimen 5 test 3 was formed by repairing a previously failed virgin specimen with special (low shrinkage) concrete as well as with 5 layers of CFRP forming the partial confinement. An additional two $(+2)$ CFRP layers were applied at the part of the section where the anchor bolts were placed. This repaired specimen failed in compression with a modest increase $(31 \%)$ in its capacity when compared with the capacity of the virgin unconfined specimen. The effectiveness of the partial confinement in this case was classified as considerable. This was due to an alteration in the anchoring of the partial confinement which proved to be 
relatively successful. The limit state for this specimen commenced with the tensile failure of the CFRP layers at the central zone and was accompanied, as expected, by a consequent compressive failure of the neighbouring weak part of the section. This is depicted in figure 10 where the anchor bolts, which were left intact, are also shown. As mentioned in section 3.1, the comparison in figure 11 is extended to include specimen 4 (Test 1), in which the partial confinement exhibited low effectiveness due to the failure of the anchor bolts.

\subsection{Very effective partial confinement}

In figure 13, the behaviour of specimens 5 (Test 4) and 5a (Test 2) is compared with the behaviour of specimens 1 test 1 (with no partial confinement) and 5 (Test 3) discussed in section 3.2. Specimens 5 (Test 4) and 5a (Test 2) were formed by repairing previously failed specimens with partial confinement of 7 layers of CFRP. Moreover, all the anchoring of their partial confinement was made with bolts going through the whole width of the strong part of the repaired section (see Table 3 and figure 3). In order to avoid the compression failure of the strong part the effectiveness of the closed hoops was enhanced as shown in figure 12 by welding. As can be seen in figure 13, a substantial increase (40\%), in the bearing capacity as well as in the deformability, resulted from the described partial confinement for these two specimens. Their behaviour was in this way better than the behaviour of specimen 4 (Test 1) which was classified before as one of considerable effectiveness of the partial confinement (section 3.2). The anchor bolts, which were left intact, are also shown in figure 14 together with the failure of the CFRP layers of the mid-part.

\section{Conclusions}

1. The undesired compression failure expected to develop in the base of vertical members with reinforced concrete cross sections having $\mathrm{h} / \mathrm{b}$ ratio larger than 1.5 under combined vertical loads and seismic actions is studied through specially formed specimens subjected to uniform compression. The retrofitting of such specimens with partial CFRP confinement is aimed at prohibiting, up to point, such compression failure. This type of partial confinement may also be applied to upgrading vertical structural members with non-accessible sides.

2. From the results of the experimental investigation with identical specimens, with or without this type of partial CFRP confinement, the successful application of such partial confinement was demonstrated. An increase of almost $50 \%$ was observed in the compression bearing capacity of some of the tested specimens. Moreover, the deformability of these specimens was substantially increased, demonstrating the effectiveness of this type of partial confinement.

3. It was found from the experimental sequence that critical factors for this increase were the type of anchorage of the CFRP partial confinement and the number of CFRP layers. Successful anchoring of the CFRP layers allowed this partial confinement to become effective and to permit the use of a larger number 
of CFRP layers. In the present study alternative anchoring schemes were tried with limitations imposed by the geometry of the model cross-section. Similar limitations imposed by the geometry and the reinforcement of the cross-section will also dictate the design of such an anchoring scheme for a prototype crosssection. Further investigation on the performance of such prototype anchoring arrangements may be necessary.

\section{Acknowledgements}

This work has been partially supported by the European Union, Project EVG1CT-2001-00040. The project is funded by the RESEARCH DG of the European Commission within the context of the Environment Program "Global Change and Natural Disasters" and is here gratefully acknowledged.

\section{References}

[1] Kawashima, K. (2000), Seismic performance of RC bridge piers in Japan: an evaluation after the 1995 Hyogo-ken nanbu earthquake, Prog. Struct. Engng Mater. 2000; 2: 82-91.

[2] Manos, G.A., Kourtides, V., Yasin, B. \& Soulis, V.J. (2004), Dynamic and Earthq. Response of Model Structures at the Volvi - Greece European Test Site, $13^{\text {th }}$ WCEE, Vancouver, Canada,. No.787.

[3] Manos, G., Renault, P. \& Sextos, A. (2005), Investigating the design implications of the influence between neighboring model structures at the Euroseistest site, Proceedings of EURODYN 2005.

[4] Pinto A. V., editor (1996), Pseudodynamic and Shaking Table Tests on R.C. Bridges. ECOEST PREC*8 Report No. 8, November 1996.

[5] Tsonis, G (2004) "Seismic Assessment and Retrofit of Existing Reinforced Concrete Bridges”, Ph.D. Thesis, Politecnico di Milano. 